\title{
Ulna hypoplasia-intellectual disability syndrome
}

INSERM

\section{Source}

INSERM. (1999). Orphanet: an online rare disease and orphan drug data base. Ulna hypoplasia-intellectual disability syndrome. ORPHA:2249

Ulna hypoplasia - intellectual deficit is a very rare syndrome characterized by mesomelic shortness of the forearms, bilateral clubfeet, aplasia or hypoplasia of all nails and severe psychomotor retardation. 